\title{
An Assessment of HIV Counselling and Testing (HCT) Service Utilization in Nigeria: A Binary Logistic Regression Approach
}

\author{
Onemayin Kolawole Jospeh ${ }^{1}$, Halid Omobolaji Yusuf ${ }^{2}$, Obafemi Oluwafemi Samuel ${ }^{1}$, \\ Adetunji Ademola Abiodun ${ }^{3, *}$ \\ ${ }^{1}$ Department of Mathematics and Statistics, Federal Polytechnic, Ado Ekiti, Nigeria \\ ${ }^{2}$ Department of Statistics, Ekiti State University, Ado-Ekiti, Nigeria \\ ${ }^{3}$ Department of Statistics, Federal Polytechnic, Ile-Oluji, Nigeria
}

Email address:

adeadetunji@fedpolel.edu.ng (A. A. Adetunji)

${ }^{*}$ Corresponding author

To cite this article:

Onemayin Kolawole Jospeh, Halid Omobolaji Yusuf, Obafemi Oluwafemi Samuel, Adetunji Ademola Abiodun. An Assessment of HIV Counselling and Testing (HCT) Service Utilization in Nigeria: A Binary Logistic Regression Approach. International Journal of HIV/AIDS Prevention, Education and Behavioural Science. Vol. 5, No. 1, 2019, pp. 26-36. doi: 10.11648/j.ijhpebs.20190501.14

Received: February 13, 2019; Accepted: March 15, 2019; Published: April 8, 2019

\begin{abstract}
HIV infection remains the most challenging health and development crisis in the last two decades as it continues to create health and socio-economic challenges in many parts of Nigeria and the world at large. HIV counselling and testing (HCT) can identify infection in early stages as it involves analysis of body fluids for the presence of antigens or antibodies produced in response to HIV and these are key to controlling the HIV epidemics. As a result, certain factors are considered in this study as deterrents to HCT service utilization in Nigeria applying the k-order binary logistic regression model using a structured questionnaire developed by the research team in some selected states in South-West of Nigeria. The sociodemographic details of respondents reveals that out of 788 people (out of 800 administered questionnaires) that were interviewed, 452 (57.4\%) have had HCT while 336 (42.6\%) never had HCT. Age 15-19 (the adolescent) with 68.1\% are the groups with the highest respondents with HCT uptake. The chi-square test of independence also reveals that age, gender, religion, and marital status are not related with HCT uptake while ethnic, educational status, place of residence are associated with decision on HCT uptake. The binary logistic regression of HCT uptake on the investigated socio-demographic details of respondents reveals the age group (50 and above) has the highest odds of up-taking HCT while those in the group 25-29 years has the least. Male respondents have a slightly higher odds compared to female and the Yoruba ethnic group are the most likely to utilize HCT. Results also revealed that traditionalist are the most likely to utilize HCT (1.635) with the Christianity (with 1.000 ) being the least. Those who are single/never married has a non-significant highest odds (1.092) among the marital status considered while those who are separated/divorced has the least (0.712). The odds of utilizing HCT is least among those with no formal education. People with Primary education are about three times more likely to take HCT compared to those with no formal education. Rural settlers are about three times (2.818) more likely to uptake HCT in comparison with those who reside in urban centres. Finally, employment status of respondents is insignificant to HCT uptake, although the odds in favour of those that are schooling is highest (1.175), followed by those that are self-employed (1.013).
\end{abstract}

Keywords: HIC, Counselling, Testing, Deterrent, Binary Logistics Regression

\section{Introduction}

HIV infection remains the most challenging health and development crisis in the last two decades as it continues to create health and socio-economic challenges in many parts of Nigeria and the world at large. Globally, the HIV epidemic has stabilized, although with unacceptably high levels of new HIV infections and AIDS deaths, there were estimated 33 million persons living with HIV at the end of 2015 out of 
which 12.5 million are young people (aged 1-24 years) with new HIV infection at 2.7 million in 2015 [1]. The annual number of new infections declined from 3.0 million in 2001 to 2.7 million in 2015. Overall, 2.0 million died due to AIDS in 2015, compared with an estimated 1.7 million in 2001 and the Sub-Saharan African nations remain the region most affected by HIV. Among regions of the world, Sub-Saharan Africa has the leading cause of death due to AIDS [2] with about $68 \%$ of worldwide infection [3] and about three-quarter of all youth in the world living with HIV despite being home only to on-tenth of the youth worldwide. HIV has claimed about 25 million lives worldwide with staggering economic and social impacts. The disease affects individuals, families, communities, nations and their economies by causing life threatening symptoms and sometimes premature deaths at productive ages [4].

In Nigeria, 2.98 million people are estimated to be living with HIV in 2009, only second to South Africa [5] but this figure has risen to 3.1 million by 2017 . Nigeria stands at a critical point where increased prevention and treatments efforts today could help avert much more significant epidemic in future. The HIV epidemic in Nigeria has been classified as a mixed epidemic with the burden of disease greater among certain high risk groups [6]. As the most populous country in Africa and one of the most populous nations in the world, a small increase in HIV/AIDS prevalence rate in Nigeria would represent a significant threat to the global HIV/AIDS burden.

HIV testing can identify infection in early stages as it involves analysis of blood or body fluids for the presence of antigens or antibodies produced in response to HIV. There are HCT (HIV counselling and testing) centres located in several medical facilities in the country. HCT services are now being offered in various settings including sexually transmitted infection (STI) clinics and general outpatient clinics as well as in field settings by mobile testing means. HCT forms the gateway to HIV prevention, treatment, care and support interventions and has been found to be effective [7-9]. It consist of two processes namely HIV counselling and HIV testing. The counselling process is confidential and also divided into two parts namely pre-test and post-test counselling. The pre-test counselling assists individuals and or couples to consider their risk of acquiring or transmitting HIV. It also helps them determine whether to be tested or not. The post-test counselling provides support when the individuals receive the test results. HCT strategies serve as important tools for identifying $\mathrm{HIV}$-infected persons, a necessary first step in accessing HIV care [10]. HCT has proven to be a cost effective ways for preventing HIV in the developing countries.

In order to achieve global zero prevalence rate of HIV, HCT services must be optimally utilized [11]. Low uptake of HCT services by people living with HIV/AIDS often times increases the prevalence rate of HIV/AIDS since people who are HIV negative may not be counselled while people living with the virus may not access appropriate treatment and care consequently leading to the inevitable spread of the infection.
One of the ways out of this problem is through the identification and analysis of the present level of utilization and the deterrents to utilization of these HCT centres by people either uninfected or people living with HIV/AIDS in Nigeria. This will help to provide recommendations on the HCT utilization rate, odds ratio in favour or against uptake and probability that an average individual will uptake HCT.

High knowledge about HIV Voluntary Test and Counselling (VCT) has not led to increase in HCT uptake $[12,13]$. HCT interventions are key to controlling the HIV epidemic [14, 15]. About $67 \%$ of new HIV infections in West Africa in 2017 occurred in Nigeria. Despite achieving a 5\% reduction in new infections between 2010 and 2017 [3], Nigeria along with South Africa and Uganda accounts for about $50 \%$ of all new HIV infections in sub-Saharan Africa every year [16].

In West and Central Africa reported infections, Nigeria alone accounted for 59\% of all new cases in 2016 [17]. Also, in $2016,34 \%$ of adults living that were HIV positive were aware of their status [18]. With Nigeria's aims of reaching UNAIDS target of having $90 \%$ of people living with HIV knowing their status by 2021[19], HIV testing in Nigeria is relatively low with only $15.1 \%$ of people from age 15 to 49 years got tested in the last 12 months [20]. A lot of reasons had been associated with why people are not interested in HCT in Nigeria. Some of these include testing kits supply and logistic issues with getting further supplies. A common belief among residents is that HCT centres are where HIVpositive people go for care, rather than being a testing centres [21].

Significant efforts are being made in the sub-Saharan African towards expanding HCT in order to reach a wider population and slow the spread of HIV [22] but most of these efforts are yet to bring about much needed change. Focal point of HCT interventions are the young people in most African countries. However, HCT uptake among these group (15 to 24 years) in Nigeria is very low [23]. Young people often indicate willingness for HCT, yet only few have accessed the service hence causing a huge gap between willingness and the actual uptake [7, 23].

Despite the importance of HCT, access and uptake remain quite low [10, 24, 25] particularly in rural areas [26]. Like other countries of the world, uptake of HCT services remain very low in Nigeria as the scourge of HIV/AIDS remains a major global public health problem, with death toll of over three million recorded per year. Many factors have been associated with low uptake including low perceived risk of infection, lack of resources necessary to provide HCT at all sites with identified need and intense stigma associated with HIV leads to ambivalence towards HIV testing [26]. As a result, certain factors are considered in this study as deterrents to HCT service utilization in Nigeria. These include quality of medical equipment, misconception of HCT services, economic barriers, and location of HCT centres to mention of a few.

To this end we apply the k-order binary logistic regression model of the form 


$$
\ln \left(\frac{p_{i}}{1-p_{i}}\right)=\beta_{0}+\beta_{1} X_{1 i}+\cdots+\beta_{k} X_{k i}+\mu_{i}
$$

Where $p_{i}$ is the probability that an individual uptakes HCT services regularly or not, $X$ 's are explanatory variables (the deterrents), $\beta_{i}$ 's are the parameters and $\mu_{i}$ is the disturbance error term.

\section{Materials and Methodology}

The research team developed a structured questionnaire that was administered to the literate respondents by a team of enumerators employed for the purpose. Responses from the non-literate respondents were filled by research assistant who understands the language of the respondents. The questionnaire was divided into several sections which include the socio-demographic details of the respondents (age, sex, ethnicity, religion, occupation, marital status, and educational status), knowledge and awareness on HCT services, knowledge on location of HCT services, myth and misconception about HCT services, etc. Frequency table and simple bar chart are used to describe the socio-demographic details of the respondents, and to compare responses on some different variables that could affect uptake of HCT. The Pearson's Chi-square of independence is used to examine relationship between the selected variables and HCT uptake.

The binary logistic regression is the most common method to analyze binary response data [27]. It is used to model relationships between the response variable and several explanatory variables, which may be discrete or continuous, that is, when the response, $\boldsymbol{Y}$, can only take one of two possible values. The responses may be Yes/No, Alive/Dead, Present/absent; etc. For analysis purpose, it is easier to denote the two levels by 0 and 1 ("failure" or "success"). The model can be used to predict the probability of the occurrence of an event and that the adequacy of the data on the logistic curve. It may also be used to predict odds of being in a case based on the values of the independent variables $[28,29]$

Efficiency of logistic regression has been proven in analyzing categorical data $[30,31,32]$. The response variable defined as "Ever tested for HIV" is a categorical variable and thus requires use of the logistic regression approach.

The main objective is to investigate the relationship between the response probability $\pi=\pi(x)$ and the explanatory variables $x_{1}, x_{2}, \ldots, x_{n}$.

A binary random variable can be defined as:

$$
Y=\left\{\begin{array}{l}
1 \text { if theoutcomeisasuccess } \\
0 \text { iftheoutcomeisafailure }
\end{array}\right.
$$

with probabilities $\mathrm{P}(\mathrm{Y}=1)=\pi$ and $\mathrm{P}(\mathrm{Y}=0)=1-\pi$.

Suppose $\mathrm{X}_{\mathrm{i}}$ is a random variable and $\mathrm{Y}_{\mathrm{i}}=1$ for the occurrence of an event of interest and 0 if otherwise then

$$
P_{i}=E\left(Y=1 / X_{i}\right)=\left(\frac{1}{1+e^{-Z}}\right)
$$

Where $Z=\beta_{0}+\beta_{1} X_{1 i}+\cdots+\beta_{k} X_{1 k}$

The equation represents what is known as the (cumulative) logistic distribution function. It is easy to verify that as $\mathrm{Z}$ ranges from $-\infty$ and $\infty, p_{i}$ ranges between 0 and 1 and that $p_{i}$ is nonlinearly related to $\mathrm{Z}$ through $X_{i}$. In a bid to satisfy these requirements, an estimation problem will be created because $p_{i}$ is non-linear in $X_{i}$ but also $\beta_{i}$ 's as can be seen in the equation below. This violation of assumption makes OLS procedure inappropriate for estimating $\beta_{i}$ 's.

To fit a binary logistic regression model, a set of regression coefficients that predict the probability of the outcome of interest are estimated. Given probability that an individual will uptake HCT as $p_{i}$ and $1-p_{i}$ for not using HCT, the probabilities results in a linear combination as:

$$
\begin{aligned}
\ln \left(\frac{\operatorname{prob}(\text { event })}{1-\operatorname{prob}(\text { event })}\right) & =\ln \left(\frac{p_{i}}{1-p_{i}}\right) \\
= & \beta_{0}+\beta_{1} X_{1}+\beta_{2} X_{2}+\ldots+\beta_{k} X_{k}
\end{aligned}
$$

The equation above has been extensively applied to numerous real life situations [27, 33-35]. The quantity to the left of the equal sign is called a logit. It's the log of the odds that an event occurs. The coefficients in the logistic regression model tell how much the logit changes based on the values of the predictor variables. When there are more than two events, binary logistics regression model can be extended to multinomial regression model.

The general linear logistic regression model can also be rewritten in terms of the probability of a positive response:

$$
\pi_{i}=\frac{\exp \left(\beta_{i 0}+\beta_{i 1} x_{i 1}+\cdots+\beta_{i p} x_{i p}\right)}{1+\exp \left(\beta_{i 0}+\beta_{i 1} x_{i 1}+\cdots+\beta_{i p} x_{i p}\right)}
$$

Above equationis the probability of the event of interest occurring given the covariates.

\section{Results and Discussion}

The socio-demographic details of respondents (table 1) reveals that out of 788 people (out of 800 administered questionnaires) that were interviewed, 452 (57.4\%) have had HCT while 336 (42.6\%) never had HCT, this supports the findings by Like other researches $[26,36]$ where a little above average of respondents have had HCT. Among the age groups considered, age $15-19$ (the adolescent) with $68.1 \%$ are the groups with the highest respondents with HCT uptake while age group $25-29$ with $48.4 \%$ of the respondents that have had HCT is the least. The chi-square test of independence also reveals that age is not related with HCT uptake. Result also shows that gender of respondents is independent of decision for HCT uptake with about $57 \%$ of both gender responded to have had HCT. In support of findings [37], ethnic of respondent is found to be associated with decision on HCT uptake with $65.7 \%$ of Yoruba, $55.7 \%$ of Igbo, and $43.1 \%$ of Hausa responded to have had HCT. Religion is independent of decision on HCT uptake although the percentage of Muslim that have had HCT $(63.6 \%)$ is 
slightly higher than the Christian (55.5\%). This is also supported by the research by [38]. Married people with $58.6 \%$ HCT uptake have the highest percentage among other marital status and widow/widower have least HCT uptake percentage, though the marital status is independent of HCT uptake as also noted [37]. At 10\% level of significance, educational status of respondent is significant to HCT uptake but not significant at 5\% level. Respondents with no formal education has the least percentage HCT uptake. Place of residence is dependent on HCT uptake with those who stay in rural areas $(71.6 \%)$ more likely to uptake HCT compared with those staying in urban centres (53.3\%). Employment status respondents is not associated with HCT uptake though students (those currently schooling) are the group with highest percentage of HCT uptake.

Table 1. Socio-demographiccharacteristicsof respondents and uptake of HCT.

\begin{tabular}{|c|c|c|c|c|}
\hline \multirow[b]{2}{*}{ Characteristics } & & \multicolumn{2}{|c|}{ Have you ever had HCT? } & \multirow[b]{2}{*}{ Chi-Square P-value ( $\alpha=0.05)$} \\
\hline & & $\begin{array}{l}\text { No } \\
n=336(42.6 \%) \\
\end{array}$ & $\begin{array}{l}\text { Yes } \\
n=452(57.4 \%)\end{array}$ & \\
\hline Age & Total (\%) & & & 0.217 \\
\hline $15-19$ & $69(8.8 \%)$ & $22(31.9 \%)$ & $47(68.1 \%)$ & \\
\hline $20-24$ & $130(16.5 \%)$ & $56(43.1 \%)$ & $74(56.9 \%)$ & \\
\hline $25-29$ & $157(19.9 \%)$ & $81(51.6 \%)$ & $76(48.4 \%)$ & \\
\hline $30-34$ & $148(18.8 \%)$ & $58(39.2 \%)$ & $90(60.8 \%)$ & \\
\hline $35-39$ & $106(13.5 \%)$ & $45(42.5 \%)$ & $61(57.5 \%)$ & \\
\hline $40-44$ & $52(6.6 \%)$ & $23(44.2 \%)$ & $29(55.8 \%)$ & \\
\hline $45-49$ & $45(5.7 \%)$ & $19(42.2 \%)$ & $26(57.8 \%)$ & \\
\hline 50 and above & $81(10.3 \%)$ & $32(39.5 \%)$ & $49(60.5 \%)$ & \\
\hline Gender & Total $(\%)$ & & & 0.824 \\
\hline Male & $346(43.9 \%)$ & $146(42.2 \%)$ & $200(57.8 \%)$ & \\
\hline Female & $442(56.1 \%)$ & $190(43.0 \%)$ & $252(57.0 \%)$ & \\
\hline Ethnicity & Total (\%) & & & 0.000 \\
\hline Yoruba & $388(49.2 \%)$ & $133(34.3 \%)$ & $255(65.7 \%)$ & \\
\hline Igbo & $203(25.8 \%)$ & $90(44.3 \%)$ & $113(55.7 \%)$ & \\
\hline Hausa & $51(6.5 \%)$ & $29(56.9 \%)$ & $22(43.1 \%)$ & \\
\hline Others & $146(18.5 \%)$ & $84(57.5 \%)$ & $62(42.5 \%)$ & \\
\hline Religion & Total $(\%)$ & & & 0.220 \\
\hline Christianity & $611(77.5 \%)$ & $272(44.5 \%)$ & $339(55.5 \%)$ & \\
\hline Islam & $158(20.1 \%)$ & $58(36.7 \%)$ & $58(63.3 \%)$ & \\
\hline Traditional & $17(2.2 \%)$ & $5(29.4 \%)$ & $12(70.6 \%)$ & \\
\hline Others & $2(0.3 \%)$ & $1(50 \%)$ & $1(50 \%)$ & \\
\hline Marital Status & Total $(\%)$ & & & 0.804 \\
\hline Married/Living together & $372(47.2 \%)$ & $154(41.4 \%)$ & $218(58.6 \%)$ & \\
\hline Separated/Divorced & $48(6.1 \%)$ & $22(45.8 \%)$ & $26(54.2 \%)$ & \\
\hline Widow/Widower & $37(4.7 \%)$ & $18(48.6 \%)$ & $19(51.4 \%)$ & \\
\hline Single/Never married & $331(42.0 \%)$ & $142(42.9 \%)$ & $189(57.1 \%)$ & \\
\hline Educational Status & Total $(\%)$ & & & 0.052 \\
\hline No formal education & $82(10.4 \%)$ & $46(56.1 \%)$ & $36(43.9 \%)$ & \\
\hline Primary & $58(7.4 \%)$ & $19(32.8 \%)$ & $39(67.2 \%)$ & \\
\hline Secondary/Vocational & $247(31.3 \%)$ & $106(42.9 \%)$ & $141(57.1 \%)$ & \\
\hline College/Poly./University & $337(42.8 \%)$ & $137(40.7 \%)$ & $200(59.3 \%)$ & \\
\hline Post-graduate & $64(8.1 \%)$ & $28(43.8 \%)$ & $36(56.3 \%)$ & \\
\hline Residence & Total (\%) & & & 0.000 \\
\hline Urban & $612(77.7 \%)$ & $286(46.7 \%)$ & $326(53.3 \%)$ & \\
\hline Rural & $176(22.3 \%)$ & $50(28.4 \%)$ & $126(71.6 \%)$ & \\
\hline Occupation & Total (\%) & & & 0.156 \\
\hline Employed & $255(32.4 \%)$ & $112(43.9 \%)$ & $143(56.1 \%)$ & \\
\hline Self-employed & $294(37.3 \%)$ & $127(43.2 \%)$ & $167(56.8 \%)$ & \\
\hline Unemployed & $89(11.3 \%)$ & $37(41.6 \%)$ & $52(58.4 \%)$ & \\
\hline Schooling & $124(15.7 \%)$ & $44(35.5 \%)$ & $80(64.5 \%)$ & \\
\hline Others & $26(3.3 \%)$ & $16(61.5 \%)$ & $10(38.5 \%)$ & \\
\hline
\end{tabular}

Source: 2019 HCT uptake Survey

Examining the effects of knowledge and awareness on HCT uptake, table 2 reveals that responses from factors considered are significant to the HCT uptake except "knowledge of HCT centres". Higher percentage (61.3\%) of those that have had HCT believed that to a great extent that "Increasing awareness programs on HIV has improved HCT service uptake thereby controlling the spread of the disease" and $(50.2 \%)$ responded that they learnt about HCT on the radio and social media. The other two factors have impact on having HCT to some extent with relatively higher percentage compared to the responses on "Not at all". 
Table 2. Association between Knowledge and awareness on HCT services and uptake of HCT.

\begin{tabular}{|c|c|c|c|}
\hline \multirow[b]{2}{*}{ Factor } & \multicolumn{2}{|c|}{ Have your ever used HCT? } & \multirow[b]{2}{*}{$\begin{array}{l}\text { Chi-Square } \\
\text { P-value }(\alpha=0.05)\end{array}$} \\
\hline & $\begin{array}{l}\text { No } \\
n=336(42.6 \%)\end{array}$ & $\begin{array}{l}\text { Yes } \\
\mathrm{n}=452(57.4 \%)\end{array}$ & \\
\hline \multicolumn{4}{|c|}{$\begin{array}{l}\text { Increasing awareness programs on HIV has improved HCT service uptake thereby } \\
\text { controlling the spread of the disease. }\end{array}$} \\
\hline To a great extent & $164(48.8 \%)$ & $277(61.3 \%)$ & \multirow[t]{3}{*}{0.001} \\
\hline To some extent & $136(40.5 \%)$ & $146(32.3 \%)$ & \\
\hline Not at all & $36(10.7 \%)$ & $29(6.4 \%)$ & \\
\hline \multicolumn{3}{|c|}{ I do not know where HCT centres are situated, this reduces the uptake of HCT services } & \multirow{5}{*}{0.097} \\
\hline To a great extent & $70(20.8 \%)$ & $124(27.4 \%)$ & \\
\hline To some extent & $200(59.5 \%)$ & $251(55.5 \%)$ & \\
\hline Not at all & $66(19.6 \%)$ & $77(17.0 \%)$ & \\
\hline \multicolumn{3}{|c|}{$\begin{array}{l}\text { I never thought of using HCT services because I do not know specific centres where } \\
\text { testing will be carried out }\end{array}$} & \\
\hline To a great extent & $74(22.0 \%)$ & $172(38.1 \%)$ & \multirow{2}{*}{0.000} \\
\hline To some extent & $187(55.7 \%)$ & $171(37.8 \%)$ & \\
\hline Not at all & $75(22.3 \%)$ & $109(24.1 \%)$ & \multirow{5}{*}{0.000} \\
\hline \multicolumn{3}{|c|}{ I learnt about the availability of $\mathrm{HCT}$ on the radio and social media } & \\
\hline To a great extent & $151(44.9 \%)$ & $227(50.2 \%)$ & \\
\hline To some extent & $102(30.4 \%)$ & $126(27.9 \%)$ & \\
\hline Not at all & $83(24.7 \%)$ & $99(21.9 \%)$ & \\
\hline
\end{tabular}

Source: 2019 HCT uptake Survey

"Testing centres located in rural areas do not have adequate supply of electricity and other basic amenities" is not a significant factors on having HCT or not (table 3). "Accessibility of HCT centres", has a significant effect on up-taking HCT with higher percentage of responses indicating the transportation and accessibility related factor affect the uptake to an extent.

Table 3. Association between Location of HCT Services and uptake of HCT.

\begin{tabular}{|c|c|c|c|}
\hline \multirow[b]{2}{*}{ Factor } & \multicolumn{2}{|c|}{ Have your ever used HCT? } & \multirow{2}{*}{$\begin{array}{l}\text { Chi-Square P-value } \\
(\alpha=0.05)\end{array}$} \\
\hline & $\begin{array}{l}\text { No } \\
n=336(42.6 \%)\end{array}$ & $\begin{array}{l}\text { Yes } \\
\mathrm{n}=\mathbf{4 5 2}(\mathbf{5 7 . 4 \%} \%\end{array}$ & \\
\hline \multicolumn{4}{|c|}{ Location of HCT centres are mostly remote and not central making it almost inaccessible } \\
\hline To a great extent & $88(26.2 \%)$ & $192(42.5 \%)$ & \\
\hline To some extent & $182(54.2 \%)$ & $193(42.7 \%)$ & 0.000 \\
\hline Not at all & $66(19.6 \%)$ & $67(14.8 \%)$ & \\
\hline \multicolumn{4}{|c|}{ Road network linking centres are usually bad and discouraging } \\
\hline To a great extent & $46(13.7 \%)$ & $121(26.8 \%)$ & 0.000 \\
\hline To some extent & $211(62.8 \%)$ & $252(55.8 \%)$ & \\
\hline Not at all & $79(23.5 \%)$ & $79(17.5 \%)$ & \\
\hline \multicolumn{4}{|c|}{$\begin{array}{l}\text { Testing centres located in rural areas do not have adequate supply of electricity and other } \\
\text { basic amenities }\end{array}$} \\
\hline To a great extent & $160(47.6 \%)$ & $219(48.5 \%)$ & 0.540 \\
\hline To some extent & $115(34.2 \%)$ & $164(36.3 \%)$ & \\
\hline Not at all & $61(18.2 \%)$ & $69(15.3 \%)$ & \\
\hline \multicolumn{4}{|c|}{$\begin{array}{l}\text { Establishment ofHCT centres in only strategic locations prevent people from readily having } \\
\text { HCT service delivery at their door-steps }\end{array}$} \\
\hline To a great extent & $100(29.8 \%)$ & $179(39.6 \%)$ & 0.017 \\
\hline To some extent & $169(50.3 \%)$ & $195(43.1 \%)$ & \\
\hline Not at all & $67(19.9 \%)$ & $78(17.3 \%)$ & \\
\hline
\end{tabular}

Source: 2019 HCT uptake Survey

Table 4 shows that "Misconception and prejudice of one's character and status emanating from being seen in testing centre limits voluntary uptake of HCT services" is rated first by the respondents on effect of myth and misconception on HCT uptake. Most respondents do not "believe that counselors would inject them with drugs capable of killing tested positive". "Misconception and prejudice of one's character and status emanating from being seen in testing centre limits voluntary uptake of HCT services" is not significant in the choice of HCT uptake. 
Table 4. Association between Myth and Misconception about HCT Services and uptake of HCT.

\begin{tabular}{|c|c|c|c|}
\hline \multirow[b]{2}{*}{ Factor } & \multicolumn{2}{|c|}{ Have your ever used HCT? } & \multirow{2}{*}{$\begin{array}{l}\text { Chi-Square } \\
\text { P-value } \\
(\alpha=0.05)\end{array}$} \\
\hline & $\begin{array}{l}\text { No } \\
\mathrm{n}=336(42.6 \%)\end{array}$ & $\begin{array}{l}\text { Yes } \\
\mathrm{n}=452(57.4 \%)\end{array}$ & \\
\hline \multicolumn{4}{|c|}{ I believe counselors would inject me with drugs capable of killing me if I test positive } \\
\hline To a great extent & $76(22.6 \%)$ & $172(38.1 \%)$ & \multirow{3}{*}{0.000} \\
\hline To some extent & $86(25.6 \%)$ & $101(22.3 \%)$ & \\
\hline Not at all & $174(51.8 \%)$ & $179(39.6 \%)$ & \\
\hline \multicolumn{4}{|c|}{ People that printed lists of names and test results will be pasted on the wall of the counseling office } \\
\hline To a great extent & $42(12.5 \%)$ & $123(38.1 \%)$ & \multirow[t]{4}{*}{0.000} \\
\hline To some extent & $123(36.6 \%)$ & $162(22.3 \%)$ & \\
\hline Not at all & $171(50.9 \%)$ & $167(39.6 \%)$ & \\
\hline \multicolumn{3}{|c|}{$\begin{array}{l}\text { Misconception and prejudice of one's character and status emanating from being seen in testing } \\
\text { centre limits voluntary uptake of HCT services }\end{array}$} & \\
\hline To a great extent & $112(33.3 \%)$ & $184(40.7 \%)$ & \multirow[t]{4}{*}{0.107} \\
\hline To some extent & $146(43.5 \%)$ & $174(38.5 \%)$ & \\
\hline Not at all & $78(23.2 \%)$ & $94(20.8 \%)$ & \\
\hline \multicolumn{3}{|c|}{$\begin{array}{l}\text { It is generally believed that an individual who test positive may besecluded and prevented from } \\
\text { going home }\end{array}$} & \\
\hline To a great extent & $95(28.3 \%)$ & $147(32.5 \%)$ & \multirow[t]{3}{*}{0.083} \\
\hline To some extent & $102(30.4 \%)$ & $153(33.8 \%)$ & \\
\hline Not at all & $139(41.4 \%)$ & $152(33.6 \%)$ & \\
\hline
\end{tabular}

Source: 2019 HCT uptake Survey

There is significant difference in the response of those that have had HCT and those that never had on the fear of rejection by the society on HCT uptake with both groups agreeing that the factor highly deterred people from uptaking HCT. In fact, all factors investigated on fear of stigmatization and social exclusion are deterrent on the uptake with high percentage responses on their effects.
However, "consequences of test results in relation to spouses and family" is considered the number one deterring factors while "Fear of testing positive is synonymous to knowing one's 'death-day' and the associated depression will accelerate the course of the disease" is the least deterring among the rest.

Table 5. Association between Fear of stigmatization and social exclusion and uptake of HCT.

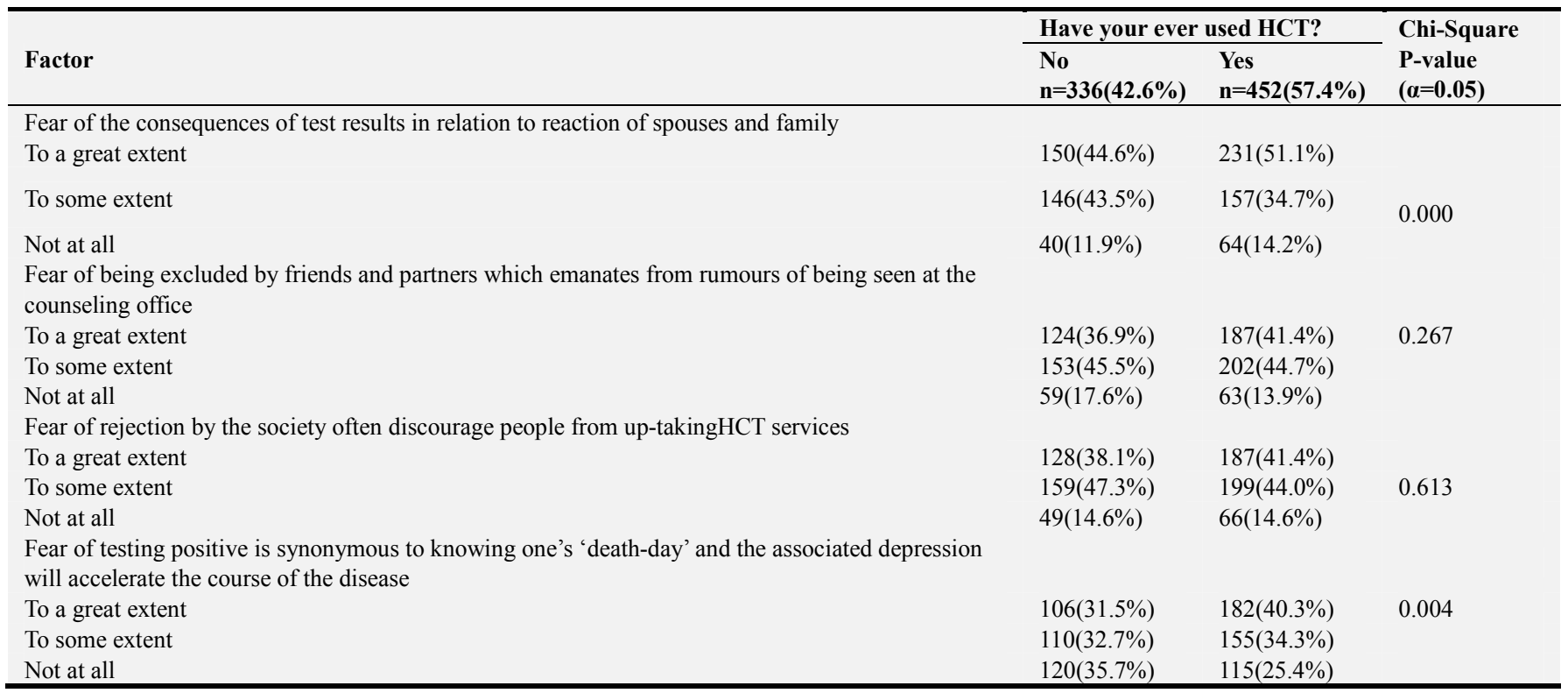

Source: 2019 HCT uptake Survey

Table 6 shows that type treatment by health workers is insignificant towards HCT uptake, responses from both that had HCT and those that never had are similar for the factor. Highest percentage $(50.7 \%$ and $46.7 \%$ respectively for both that had HCT and those that never had) of respondents believed to a great extent that "Most HIV discordant couples tend to lack the required motivation to uptake HCT because of disagreement between partners". 
Table 6. Association between Lack of motivation and time and uptake of HCT.

\begin{tabular}{|c|c|c|c|}
\hline \multirow[b]{2}{*}{ Factor } & \multicolumn{2}{|c|}{ Have your ever used HCT? } & \multirow{2}{*}{$\begin{array}{l}\text { Chi-Square } \\
\text { P-value } \\
(\alpha=0.05)\end{array}$} \\
\hline & $\begin{array}{l}\text { No } \\
\mathrm{n}=336(42.6 \%)\end{array}$ & $\begin{array}{l}\text { Yes } \\
\mathrm{n}=452(57.4 \%)\end{array}$ & \\
\hline \multicolumn{4}{|c|}{ Disdainful treatment by health workers usually discourage uptake of HCT services } \\
\hline To a great extent & $153(45.5 \%)$ & $226(50.0 \%)$ & \multirow{3}{*}{0.286} \\
\hline To some extent & $123(36.6 \%)$ & $162(35.8 \%)$ & \\
\hline Not at all & $60(17.9 \%)$ & $64(14.2)$ & \\
\hline To a great extent & $143(42.6 \%)$ & $214(47.3 \%)$ & \multirow[t]{4}{*}{0.000} \\
\hline To some extent & $95(28.3 \%)$ & $160(35.4 \%)$ & \\
\hline Not at all & $98(29.2 \%)$ & $78(17.3 \%)$ & \\
\hline \multicolumn{3}{|c|}{$\begin{array}{l}\text { I do not uptake HCT services because I cannot maintain standard of dress and appearance in the } \\
\text { centre }\end{array}$} & \\
\hline To a great extent & $60(17.9 \%)$ & $147(32.5 \%)$ & \multirow[t]{2}{*}{0.000} \\
\hline Not at all & $150(44.6 \%)$ & $161(35.6 \%)$ & \\
\hline \multicolumn{3}{|c|}{$\begin{array}{l}\text { Most HIV discordant couples tend to lack the required motivation to uptake HCT because of } \\
\text { disagreement between partners }\end{array}$} & \multirow{4}{*}{0.002} \\
\hline To a great extent & $157(46.7 \%)$ & $229(50.7 \%)$ & \\
\hline To some extent & $121(36.0 \%)$ & $183(40.5 \%)$ & \\
\hline Not at all & $58(17.3 \%)$ & $40(8.8 \%)$ & \\
\hline
\end{tabular}

Source: 2019 HCT uptake Survey

Among reasons considered on how economic barriers to HCT services affect the uptake (table 7), "Not all the resources obtainable at the HCT centres are free e.g. registration cards" is the most deterring factor with $40.5 \%$ and $48.5 \%$ of those who never had HCT and those that had
HCT respectively agreeing to a great extent. Another highly deterring factor under this category is "the work schedule" of respondents with the distance and means of transportation being the least deterring factor. All the factors considered are significant at $5 \%$ level.

Table 7. Association between Economic Barriers to HCT services and uptake of HCT.

\begin{tabular}{|c|c|c|c|}
\hline \multirow[b]{2}{*}{ Factor } & \multicolumn{2}{|c|}{ Have your ever used HCT? } & \multirow{2}{*}{$\begin{array}{l}\text { Chi-Square P-value } \\
(\alpha=0.05)\end{array}$} \\
\hline & $\begin{array}{l}\text { No } \\
n=336(42.6 \%)\end{array}$ & $\begin{array}{l}\text { Yes } \\
\mathrm{n}=452(57.4 \%)\end{array}$ & \\
\hline \multicolumn{4}{|c|}{$\begin{array}{l}\text { Testing sites around here are too far and there are no means of transportation to the } \\
\text { centres }\end{array}$} \\
\hline To a great extent & $50(14.9 \%)$ & $159(35.2 \%)$ & \\
\hline To some extent & $195(58.0 \%)$ & $228(50.4 \%)$ & 0.000 \\
\hline Not at all & $91(27.1 \%)$ & $65(14.4 \%)$ & \\
\hline \multicolumn{4}{|c|}{$\begin{array}{l}\text { HCT centres are too far and remote with limited transportation means which are } \\
\text { expensive and unaffordable }\end{array}$} \\
\hline To a great extent & $59(17.6 \%)$ & $157(34.7 \%)$ & 0.000 \\
\hline To some extent & $203(60.4 \%)$ & $215(47.6 \%)$ & \\
\hline Not at all & $74(22.0 \%)$ & $80(17.7 \%)$ & \\
\hline \multicolumn{4}{|c|}{ Not all the resources obtainable at the HCT centres are free e.g. registration cards } \\
\hline To a great extent & $136(40.5 \%)$ & $219(48.5 \%)$ & \\
\hline To some extent & $118(35.1 \%)$ & $149(33.0 \%)$ & 0.048 \\
\hline Not at all & $82(24.4 \%)$ & $84(18.6 \%)$ & \\
\hline \multicolumn{4}{|c|}{$\begin{array}{l}\text { My work schedule is very tight and prevents me from making time to uptake HCT } \\
\text { services }\end{array}$} \\
\hline To a great extent & $95(28.3 \%)$ & $169(37.4 \%)$ & \\
\hline To some extent & $110(32.7 \%)$ & $174(38.5 \%)$ & 0.000 \\
\hline Not at all & $131(39.0 \%)$ & $109(24.1 \%)$ & \\
\hline
\end{tabular}

Source: 2019 HCT uptake Survey

Examining how quality of HCT service and utilization affect HCT uptake (table 8), $35.1 \%$ of those who never had HCT believed that "Lack of trust in health worker to give adequate results prevent the utilization of HCT services" affect their choice to a great extent, it is $24.4 \%$ for "lack of trust of the workers in HCT centres on the accuracy of result". However, $33.6 \%$ of those who never had HCT believed that "Quality of equipment in HCT centres around 
can be trusted". Most of the respondents believed that inadequate qualified medical personnel in HCT centres limit utilization of HCT services. All the factors considered under quality of HCT services and utilization are significant in the choice of HCT uptake by respondents. In all, lack of trust of health workers to give accurate result is the number one factor that deterred respondents on HCT uptake with a combined $(77.4 \%)$ responses for both that have had HCT and those that never had.

Table 8. Association between Quality of HCT services \& Utilization of HCT centres and uptake of HCT.

\begin{tabular}{|c|c|c|c|}
\hline \multirow[b]{2}{*}{ Factor } & \multicolumn{2}{|c|}{ Have your ever used HCT? } & \multirow{2}{*}{$\begin{array}{l}\text { Chi-Square } \\
\text { P-value } \\
(\alpha=0.05)\end{array}$} \\
\hline & $\begin{array}{l}\text { No } \\
n=336(42.6 \%)\end{array}$ & $\begin{array}{l}\text { Yes } \\
n=452(57.4 \%)\end{array}$ & \\
\hline Lack of trust in health worker to give adequate results prevent the utilization of HCT services & & & 0.000 \\
\hline To a great extent & $118(35.1 \%)$ & $191(42.3 \%)$ & \\
\hline To some extent & $146(43.5 \%)$ & $188(41.6 \%)$ & \\
\hline Not at all & $72(21.4 \%)$ & $73(16.2 \%)$ & \\
\hline Many of the workers in HCT centres cannot be trusted to give appropriate (accurate) results & & & 0.000 \\
\hline To a great extent & $82(24.4 \%)$ & $175(38.7 \%)$ & \\
\hline To some extent & $168(50.0 \%)$ & $200(44.2 \%)$ & \\
\hline Not at all & $86(25.6 \%)$ & $77(17.0 \%)$ & \\
\hline Inadequate qualified medical personnel in HCT centres limit utilization of HCT services & & & 0.007 \\
\hline To a great extent & $90(26.8 \%)$ & $163(36.1 \%)$ & \\
\hline To some extent & $155(46.1 \%)$ & $200(44.2 \%)$ & \\
\hline Not at all & $91(27.1 \%)$ & $89(19.7 \%)$ & \\
\hline Quality of equipment in HCT centres around cannot be trusted & & & 0.000 \\
\hline To a great extent & $77(22.9 \%)$ & $174(38.5 \%)$ & \\
\hline To some extent & $146(43.5 \%)$ & $178(39.4 \%)$ & \\
\hline Not at all & $113(33.6 \%)$ & $100(22.1 \%)$ & \\
\hline
\end{tabular}

Source: 2019 HCT uptake Survey

The output of the logistic regression (table 9) of HCT uptake on the investigated socio-demographic details of respondents reveals that age is not a significant factor to HCT uptake. However, the age group (50 and above) has the highest odds of up-taking HCT while those in the group 2529 years has the least. It is also noted that although gender of respondent is not significant variable on HCT uptake, male respondents have a slightly higher odds compared to female. Among the considered ethnic group, Yoruba (1.000) are the most likely to utilize HCT, followed by Igbo $(0.677)$ while the Hausas has the least (0.316).

Results also revealed that religion is not a significant factor in HCT uptake although the traditionalist are the most likely to utilize HCT (1.635) with the Christianity (with $1.000)$ being the least. Those who are single or never married has a non-significant highest odds (1.092) among the marital status considered while those who are separated or divorced has the least $(0.712)$. Higher disparities in odds are noted among various educational status. The odds of utilizing HCT is least among those with no formal education. People with Primary education are about three times more likely to take HCT compared to those with no formal education. The odds in favour of those with Secondary and those with college/Polytechnic/University educations are more than two times more likely (2.173 and 2.205 respectively) compared with those with no formal education. Rural settlers are about three times (2.818) more likely to uptake HCT in comparison with those who reside in urban centres. Finally, employment status of respondents is insignificant to HCT uptake, although the odds in favour of those that are schooling is highest (1.175), followed by those that are self-employed (1.013).

Table 9. Logistic regression of HCT uptake on socio-demographic factors.

\begin{tabular}{|c|c|c|c|c|}
\hline & Std. Err. & P-value & Odds Ratio & $95 \%$ C. I. for OR \\
\hline Age & & 0.657 & & \\
\hline $15-19$ (reference category) & & & 1.000 & \\
\hline $20-24$ & 0.360 & 0.347 & 0.713 & $(0.352,1.444)$ \\
\hline $25-29$ & 0.383 & 0.242 & 0.639 & $(0.301,1.353)$ \\
\hline $30-34$ & 0.420 & 0.952 & 1.025 & $(0.450,2.336)$ \\
\hline $35-39$ & 0.438 & 0.698 & 0.843 & $(0.357,1.991)$ \\
\hline $40-44$ & 0.491 & 0.816 & 0.892 & $(0.341,2.336)$ \\
\hline 50 and above & 0.480 & 0.868 & 1.083 & $(0.423,2.775)$ \\
\hline \multicolumn{5}{|l|}{ Gender } \\
\hline Male $_{\text {(reference category) }}$ & & & 1.000 & \\
\hline Female & 0.158 & 0.581 & 0.916 & $(0.672,1.250)$ \\
\hline Ethnicity & & 0.001 & & \\
\hline Yoruba & & & 1.000 & \\
\hline
\end{tabular}




\begin{tabular}{|c|c|c|c|c|}
\hline & Std. Err. & P-value & Odds Ratio & 95\% C. I. for OR \\
\hline Igbo & 0.192 & 0.041 & 0.677 & $(0.465,0.985)$ \\
\hline Hausa & 0.384 & 0.003 & 0.316 & $(0.149,0.670)$ \\
\hline Others & 0.225 & 0.004 & 0.524 & $(0.337,0.814)$ \\
\hline Religion & & 0.485 & & \\
\hline Christianity (reference category) $_{\text {(n) }}$ & & & 1.000 & \\
\hline Islam & 0.241 & 0.168 & 1.394 & $(0.870,2.233)$ \\
\hline Traditional & 0.599 & 0.412 & 1.635 & $(0.505,5.292)$ \\
\hline Others & 1.430 & 0.760 & 1.548 & $(0.094,25.537)$ \\
\hline Marital status & & 0.714 & & \\
\hline Married/Living together ${ }_{\text {(reference category) }}$ & & & 1.000 & \\
\hline Separated/Divorced & 0.345 & 0.325 & 0.712 & $(0.363,1.400)$ \\
\hline Widow/Widower & 0.417 & 0.689 & 0.847 & $(0.374,1.916)$ \\
\hline Single/Never married & 0.219 & 0.687 & 1.092 & $(0.711,1.678)$ \\
\hline Educational status & & 0.060 & & \\
\hline No formal education (reference category) & & & 1.000 & \\
\hline Primary & 0.393 & 0.006 & 2.922 & $(1.351,6.318)$ \\
\hline Secondary/Vocational & 0.324 & 0.017 & 2.173 & $(1.151,4.101)$ \\
\hline College/Polytechnic/University & 0.329 & 0.016 & 2.205 & $(1.158,4.199)$ \\
\hline Post-graduate & 0.412 & 0.105 & 1.951 & $(0.869,4.377)$ \\
\hline \multicolumn{5}{|l|}{ Place of residence } \\
\hline Urban $_{\text {(reference category) }}$ & & & 1.000 & \\
\hline Rural & 0.228 & 0.000 & 2.818 & $(1.801,4.410)$ \\
\hline Occupation & & 0.585 & & \\
\hline Employed (reference category) $_{\text {) }}$ & & & 1.000 & \\
\hline Self-employed & 0.208 & 0.950 & 1.013 & $(0.673,1.524)$ \\
\hline Unemployed & 0.301 & 0.884 & 0.957 & $(0.531,1.725)$ \\
\hline Schooling & 0.298 & 0.590 & 1.175 & $(0.655,2.107)$ \\
\hline Others & 0.491 & 0.140 & 0.485 & $(0.185,1.269)$ \\
\hline Constant & 0.562 & 0.738 & 0.829 & \\
\hline
\end{tabular}

Source: 2019 HCT uptake Survey

\section{Conclusion and Recommendation}

Access to HCT and support is the global principle for HIV intervention and prevention. HCT is a very critical entry point for other interventions. Knowing ones HIV status helps in adopting a healthier general lifestyle and hence assists in limiting the prevalence of the disease. Identified People living with HIV (PLWH) would also receive necessary counseling for healthy living and also have access to antiretroviral therapy. HCT is essential for all support and treatment interventions against HIV and AIDS, and critical to militating against HIV.

Earlier researches had reported that majority of people are always willing to do HIV testing after been counselled but it is surprising that the willingness is has not resulted into the reality. This result obtained in this research showed that out of 788 respondents, only $57.4 \%$ have had HCT which is restively low considering the impact of the HIV/AIDS scourge in the society and the relevance of status identification towards treatment. It is therefore important for government and various non-governmental agencies on HIV/AIDS related support programmes to improve sensitization on the importance of HIV/AIDS counselling and testing.

Among the socio-demographic characteristics considered, place of residence is the most significant on HCT uptake with higher percentage of up-taking coming from those in rural areas. This may not be unconnected with the fact that most of the outreach on HCT is focused on those rural with the perception that those in urban centres are enlightened enough. No matter how this may be true, efforts must be geared towards orientation and reorientation of generality of people since fear and stigmatization has been found to be a very significant deterring factor in HCT up-taking. Those with "no formal education" are most likely not to uptake HCT as reported in the study. Hence, efforts must be directed towards groups of people that are less likely to be formally educated. Battle against the scourge of HIV/AIDS should be taken to churches and mosques since a number of worshippers are found not to uptake HCT. Religion leaders should be encouraged to discuss the relevance of HCT in programmes.

As recognizable efforts are being made on awareness HIV/AIDS, more efforts should go for counselling and testing to increase status identification. HCT service centres should be made more recognizable and accessible to encourage easy utilization.

In order to instill more confidence in the counselling and testing process, HCT providers are encourage to strictly respect and adhered to the "5 Cs" (Consent, Confidentiality, Counselling, Correct test results, and Connection/linkage to prevention, care and treatment). Also, to reduce societal fear and stigmatization, more actions are required by all agencies of government and NGOs on HIV/AIDS related programmes to improve on sensitization and education of the generality of the populace on the importance of supporting those tested positive and reintegrate them into society.

Funding partners are encourage to ensure HCT uptake is 
made free by providing all necessary logistics and equipment needed. This may encourage those with financial challenges to signify interest in up-taking HCT and thereby improve on status identification. Such support may include training and retraining of HCT providers.

\section{Acknowledgements}

The authors appreciate the Tertiary Education Trust Fund's (TETFund) Institutional Based Research (IBR) Intervention line for the sponsorship of this research and the Committee of Research (Centre for Research and Innovative Development, CRID) of the Federal Polytechnic, Ado-Ekiti for the approval.

\section{References}

[1] UNAIDS (2010a). Report on the global AIDS Epidemic.

[2] UNAIDS AIDS Epidemic update (2007). Joint UN Programme in HIV/AIDS and World Health Organization, 2007.

[3] UNAIDS (20017a) 'AIDSinfo' [Accessed November, 2018]

[4] Yamano T. and Jayne T. S. (2004). "Measuring the Impacts of Working-age Adult Death on Rural Households in Kenya," World Development, vol. 32: 91-119.

[5] UNAIDS (2010) 2010 Outlook Report. Joint UN Programme in HIV/AIDS 2009. Accessed at www.unaids.org on $04 / 02 / 2019$

[6] FMH (Federal Ministry of Health) (2012). Nigeria: HIV/AIDS Country Report, pp. 1 -60.

[7] Yahaya L. A, Jimoh, A. A. G and Balogun O. R. (2010). Factors hindering acceptance of HIV and AIDS Voluntary Counselling and Testing (VCT) among youths in Kwara State, Nigeria. Journal of AIDS and HIV Research Vol. 2(7), pp. 138-143.

[8] Marks G, Crepaz N, Senterfitt J. W, Janssen RS. (2005). Metaanalysis of high-risk sexual behavior in persons aware and unaware they are infected with HIV in the United States: implications for HIV prevention programs. J AIDS; 39: 44653.

[9] UNAIDS (2002). Summary of the Declaration of Commitment on HIV/AIDS.

[10] Obermeyer C. M. and Osborn M. (2007). The utilization of testing and counselling for HIV: a review of the social and behavioural evidence, American Journal of Public Health 97(10):1762-74. 2007

[11] WHO (2012). Statement on HIV Testing and Counselling: WHO, UNAIDS re-affirm opposition to mandatory HIV testing, [Accessed February, 2019].

[12] Olugbenga-Bello A. I., Oladele E. A., Adeomi A. A. and Ajala A. (2012). Perception about HIV testing among women attending antenatal clinics at Primary Health Centres in Osogbo, Southwest, Nigeria, Journal of AIDS and HIV Research Vol. 4(4), pp. 105-112, April 2012.
[13] Mgosha, P., C., Kweka E., J., Mahande A., M., Barongo L., R., Shekalaghe S., Nkya H., M., Lowassa A., Mahande M., J. (2009). Evaluation of utilization and attitude to voluntary counselling and testing among health care professional students in Kilimanjaro region, Tanzania. BMC Public Health, 9:128.

[14] Witzel T. C, Lora W., Lees S., and Desmond N. (2017). Uptake contexts and perceived impacts of HIV testing and counselling among adults in East and Southern Africa: A meta-ethnographic review. PLoS ONE 12(2): e0170588. https://doi.org/10.1371/journal.pone.0170588.

[15] Matovu J. K. B. and Makumbi F. E. (2007). Expanding access to voluntary HIV counselling and testing in sub-Saharan Africa: alternative approaches for improving uptake, 20012007. Trop Med Int Health. 2007; 12(11): 1315-1322. pmid:17949401

[16] UNAIDS (2017b) Data Book.

[17] UNAIDS (2017c) 'Ending AIDS: Progress towards the 90-9090 targets.

[18] UNAIDS (2017d) 'Data Book'.

[19] NACA (2017) 'National Strategic Framework on HIV and AIDS: $2017-2021$

[20] National Bureau of Statistics (NBS) and United Nations Children's Fund (UNICEF) (2017) 'Multiple Indicator Cluster Survey 2016-17, Survey Findings Report'

[21] NACA (2015) 'Nigeria GARPR 2015'.

[22] Bond V. A. (2010). "It is not an easy decision on HIV, especially in Zambia": opting for silence, limited disclosure and implicit understanding to retain a wider identity. AIDS Care. 2010. 22: s6-s13.

[23] Ibrahim M., Ipadeola O., Adebayo S. and Fatusi A. (2013). Socio-demographic Determinants of HIV Counseling and Testing Uptake among Young People in Nigeria, International Journal of Prevention and Treatment, 2(3), pp. 23-31. doi: 10.5923/j.ijpt.20130203.01

[24] Azuogu B. N., Ogbonnaya L. U., Alo C. N. (2011). HIV voluntary Counselling and testing practices among military personnel and civilian residents in a military cantonment in South-Eastern Nigeria. HIV/AIDS-Research and Palliative Care, pp. 107-116

[25] DeGraft-Johnson J., Paz-Soldan V., Kasote, A. and Tsui A. O. (2005). HIV voluntary counseling and testing service preferences in a rural Malawi population. AIDS and Behavior, 9(4), 475-484.

[26] Bwambale F. M., Ssali S. N., Byaruhanga S., Kalyango J. N., Karamagi C. A. (2008). Voluntary HIV counselling and testing among men in rural western Uganda: implications for HIV prevention, BMC Public Health. 2008 Jul 30;8:263. doi: 10.1186/1471-2458-8-263.

[27] Adejumo A. O. and Adetunji A. A. (2013): Application of Ordinal Logistic Regression in the Study of Students' Performance, Journal of Mathematical Theory and Modelling, 3(11), pp $10-19$.

[28] Kleinbaum, D. G. and Klein, M. (2010) Modeling Strategy Guidelines. In: Logistic Regression, Part of the Series Statistics for Biology and Health, Springer, Berlin, 165-202. http://dx.doi.org/10.1007/978-1-4419-1742-3_6. 
[29] Park H. (2013). An Introduction to Logistic Regression: From Basic Concepts to Interpretation with Particular Attention to Nursing Domain, J Korean AcadNurs 43(2), pp. 154-164.

[30] Cox D. R. (1972). "Regression Models and Life Tables (with Discussion)." Journal of the Royal Statistical Society, Series B $34: 187-220$.

[31] Fahrmeir L. and Tutz G.(2001). Multivariate Statistical Modelling based on Generalized Linear Models (3rd edition), Springer: New York.

[32] Hosmer D. and Lemeshow S. (2001). Applied Logistic Regression (second edition), john Wiley \& Sons: New York. ISBN: 0471208264 / 0-471-20826-4.

[33] Ogunleye S. O. and Fagbohun A. B. (2009). "A Logit Regression Analysis of some Tuberculosis Data", International Journal of Numerical Mathematics Vol 4(1) pp. 1-14.

[34] Mohlabane N., Tutshana B., Peltzer K. and Mwisongo A. (2016). Barriers and facilitators associated with HIV testing uptake in South African health facilities offering HIV
Counselling and Testing, Health SA Gesondheid 21 (2016) pp. 86-95.

[35] Halid O. Y. and Akinnitire F. I. (2013). A Logit Regression Analysis of Homeowners in Nigeria, The Global Journal of Science Frontier Research, 13(3).

[36] Shisana O., Rehle T., Simbayi L., Parker W. and Jooste S. (2009). South African National Hiv Prevalence, Incidence, Behaviour and Communication Survey, 2008 HSRC Press, South Africa.

[37] Menna T., Ali A., and Worku A. (2015). Factors associated with HIV counseling and testing and correlations with sexual behavior of teachers in primary and secondary schools in Addis Ababa, Ethiopia, HIV/AIDS - Research and Palliative Care 2015:7 197-208.

[38] Amu E. O., Ijadunola K. T., Bamidele J. O. and Odu O. O. (2013). Barriers to and determinants of HIV counselling and testing among adults in Ayedaade local government area, Osun State, Nigeria, Journal of Medical Sciences, 13(8) PP 803-808. 